\title{
Increased TNF- $\alpha$ expression in cultured mouse embryos exposed to teratogenic concentrations of glucose
}

\author{
A. Torchinsky ${ }^{1}$, I. Brokhman ${ }^{1}$, J. Shepshelovich ${ }^{1}$, H. Orenstein ${ }^{1}$, S. Savion${ }^{1}$, \\ Z. Zaslavsky' ${ }^{1}$, M. Koifman ${ }^{2}$, H. Dierenfeld ${ }^{2}$, A. Fein ${ }^{1}$ and V. Toder ${ }^{1}$ \\ ${ }^{1}$ Department of Embryology and Teratology, Sackler School of Medicine, Tel-Aviv University, Tel Aviv, \\ Israel; and ${ }^{2}$ Department of Obstetrics and Gynecology, Carmel Medical Center, Haifa, Israel
}

Diabetes-induced early embryonic death is accompanied by an increased expression of tumour necrosis factor $\alpha$ (TNF- $\alpha$ ) in the embryonic microenvironment. The aim of the present study was to evaluate whether diabetesinduced embryopathic stress may also alter the expression of TNF- $\alpha$ produced by the embryo itself. As a model, whole postimplantation embryos were cultured for $24 \mathrm{~h}$ in a medium with high concentrations of glucose, one of the main diabetes-associated teratogenic metabolites. An anomaly such as an open neural tube was used as an end-point characterizing the glucose-induced teratogenic effect and the number of somites was counted to evaluate growth retardation induced by glucose. The expression of TNF- $\alpha$ (by immunohistochemistry), apoptosis (by TdTmediated dUTP nick-end labelling; TUNEL) and the activity of caspases 3 and 8 (by a fluorometric assay) were evaluated in normal and malformed embryos. Ninety-seven per cent of the embryos exposed to $1300 \mathrm{mg}$ glucose $\mathrm{dl}^{-1}$ exhibited an open neural tube. The percentage of malformed embryos was smaller in media containing 800 and 500 mg glucose $\mathrm{dl}^{-1}$ (68 and $37 \%$, respectively) but it still exceeded significantly the value registered in embryos developing in a normoglycaemic medium (12\%). In addition, a significant decrease in the number of somites was observed in embryos developing in media containing 1300 and $800 \mathrm{mg}$ glucose $\mathrm{dl}^{-1}$. Malformed embryos exhibited a greater number of nuclei that were positive in the TUNEL assay as well as a higher amount of active caspase 8 compared with normal embryos (with closed neural folds). TNF- $\alpha$ expression was detected in the neuroepithelial layer of the neural tube of the malformed embryos, whereas the expression of this cytokine was weak, if detectable, in normal embryos. Together, these findings indicate that TNF- $\alpha$ produced by the embryo may be involved in regulating the response of embryos to diabetes-generated embryopathic stress.

\section{Introduction}

Disorders of reproductive function, such as pregnancy loss and the birth of offspring with structural anomalies, in diabetic women are among the most serious complications of diabetes (Reece et al., 1996; Kjos and Buchanan, 1999). The aetiology and molecular mechanisms of diabetes teratogenicity are unknown (Eriksson et al., 2000). The role of glucose as a single aetiological factor is questioned by the birth of malformed offspring to women with well-controlled diabetes (Reece et al., 1996; Langer and Conway, 2000). Nevertheless, a positive correlation between maternal blood glucose concentration and the occurrence of fetuses with gross structural anomalies was clearly demonstrated in epidemiological (Green et al., 1989) and some experimental studies in streptozoticinand alloxan-treated diabetic mice (Torchinsky et al., 1997; Machado et al., 2001).

It has been demonstrated that teratogen-induced embryonic death or the occurrence of gross structural

Email: arkadyt@post.tau.ac.il anomalies in fetuses are often preceded by excessive apoptosis in embryonic structures of postimplantation embryos that become malformed (Mirkes, 2002; Toder et al., 2002). Apoptosis is a genetically regulated process driven by many molecules acting as activators, effectors and negative regulators (Green, 1998; Pomerantz and Baltimore, 2000). Tumour necrosis factor $\alpha$ (TNF- $\alpha$ ) acts in a cell type- and stimulus-dependent manner, to generate apoptotic signalling cascades (Baud and Karin, 2001; Gupta, 2001). The apoptotic action of TNF- $\alpha$ could occur mainly through its binding to the type $1 \mathrm{TNF}$ receptor (TNFR1), followed by the activation of caspases 8 and 3, which are considered to be among the main mediators of apoptosis (Baud and Karin, 2001; Gupta, 2001).

Studies with diabetic mice and rats revealed that synthesis of TNF- $\alpha$ increases in uterine epithelial cells at the time of implantation (Pampfer et al., 1995). Further studies revealed that blastocysts that are exposed to TNF- $\alpha$ in vitro experienced an increase in cell death, and an increased rate of resorption when these blastocysts were transferred into pseudopregnant mice (Pampfer et al., 
1997; Wuu et al., 1999). As blastocysts express TNF- $\alpha$ receptors (Pampfer et al., 1994), it has been hypothesized that these receptors might be targets for uterine TNF- $\alpha$ (Pampfer, 2001). The possibility of such a scenario is indirectly supported by studies in streptozoticinand alloxan-treated diabetic mice, which exhibit an increased amount of TNF- $\alpha$ mRNA and protein in the uterus and placenta (Fein et al., 2001) as well as a marked reduction in pregnancy rate and a high incidence of litters with severely malformed fetuses (Torchinsky et al., 1997; Machado et al., 2001)

Whereas increased expression of TNF- $\alpha$ in the embryonic microenvironment of diabetic mice was shown in numerous studies, it remains unclear whether diabetes also influences the expression of TNF- $\alpha$ produced by the embryo. At the same time, it is TNF- $\alpha$ produced by the embryo itself that may be involved in regulating the response of embryonic cells to the teratogenic stress.

The whole embryo culture of rodent early postimplantation embryos developed by New (1978) is widely used in studies addressing the aetiology and mechanisms of diabetes-induced birth defects (Sadler, 1997). In these studies, glucose at high concentration was repeatedly demonstrated to be a factor inhibiting neural tube closure (Sadler, 1997). Therefore, in the present study a whole embryo culture system was used in which five or six somite mouse embryos were cultured for $24 \mathrm{~h}$ in a medium with a high glucose concentration to investigate whether the expression of TNF- $\alpha$ is altered in early postimplantation embryos exposed to teratogenic concentrations of glucose. In addition, the study evaluated whether the changes in these embryos are accompanied by apoptosis and activation of caspases 3 and 8.

\section{Materials and Methods}

Mice

ICR mice of 6-8 weeks of age were obtained from the Tel Aviv University animal facility. The animals were maintained on a $14 \mathrm{~h}$ light: $10 \mathrm{~h}$ dark cycle with food and tap water available ad libitum. Females were caged with males overnight and the presence of a vaginal plug (11:00 $\mathrm{h}$ ) determined as day 1 of pregnancy.

Animal experiments were approved by the Ethical Committee for Animal Use of Tel Aviv University.

\section{Whole embryo culture}

Female mice were killed by cervical dislocation on day 8 of gestation. Embryos were dissected from the uterus and cultured as described by New (1978). Briefly, embryos were removed by dissection under sterile conditions, freed from Reichert's membrane and transferred to $50 \mathrm{ml}$ sterile culture tubes (three or four embryos per tube) containing a prewarmed $\left(37^{\circ} \mathrm{C}\right)$ medium consisting of $75 \%$ fetal calf serum and $25 \%$
Dulbecco's modified Eagle's medium (DMEM) (Biological Industries, Beit Haemek) supplemented by 100 iu penicillin $\mathrm{ml}^{-1}$ and $100 \mu \mathrm{g}$ streptomycin $\mathrm{ml}^{-1}$. The final glucose concentration in the culture medium was, approximately, $100 \mathrm{mg} \mathrm{dl}^{-1}$. A gas mixture consisting of $5 \% \mathrm{O}_{2}, 5 \% \mathrm{CO}_{2}$ and $90 \% \mathrm{~N}_{2}$ was passed into each tube for $3 \mathrm{~min}$ and the tubes were placed in a roller incubator (30 rev $\min ^{-1}$ ) for $24 \mathrm{~h}$.

The hyperglycaemic culture media were prepared by the addition of D-glucose to the basic (control) medium in concentrations resulting in values fivefold $(500 \mathrm{mg}$ $\mathrm{dl}^{-1}$ ), eightfold (800 mg dl-1) and 13-fold (1300 mg $\mathrm{dl}^{-1}$ ) the glucose concentration of the control medium. The osmolarity was corrected by addition of $0.31,0.5$ and $0.8 \mathrm{ml}$, respectively, of distilled $\mathrm{H}_{2} \mathrm{O}$ to a total volume of $5 \mathrm{ml}$ culture medium supplemented by 500, 800 and $1300 \mathrm{mg}$ glucose $\mathrm{dl}^{-1}$.

\section{Tissue processing}

For immunohistochemistry and TdT-mediated dUTP nick-end labelling (TUNEL), embryos were fixed in $4 \%$ $(\mathrm{w} / \mathrm{v})$ paraformaldehyde and embedded in paraffin wax and sections of $7 \mu \mathrm{m}$ thickness were prepared.

\section{TNF- $\alpha$ protein localization}

Immunostaining was performed as described by Fein et al. (2001). Briefly, tissue sections were removed from paraffin wax, washed in PBS and treated with $1.5 \mathrm{mg}$ hyaluronidase $\mathrm{ml}^{-1}$ (Sigma, St Louis, MO) in PBS. Endogenous peroxidase activity was inhibited by incubating the sections in $0.3 \%(\mathrm{v} / \mathrm{v})$ hydrogen peroxide. Non-specific binding sites were blocked by incubation in a $20 \%$ solution of fetal calf serum (FCS) in PBS$0.5 \%(\mathrm{v} / \mathrm{v})$ Tween-20 (PBST) for $30 \mathrm{~min}$ at $37^{\circ} \mathrm{C}$. Sections were stained with rabbit anti-mouse TNF- $\alpha$ antibodies at $5 \mu \mathrm{g} \mathrm{ml}^{-1}$ in $10 \%$ FCS-PBST. Subsequently, slides were washed in PBS and incubated for $30 \mathrm{~min}$ at room temperature with biotinylated goat anti-rabbit IgG (Jackson Immunoresearch Laboratories, West Grove, PA), at $1.5 \mu \mathrm{g} \mathrm{ml}^{-1}$, and then incubated in streptavidinconjugated horseradish peroxidase (streptavidin-HRP; Zymed, San Francisco, CA) in $12 \mu \mathrm{g}$ PBST $\mathrm{ml}^{-1}$. TNF$\alpha$-positive cells were visualized by incubating the sections with $0.2 \mathrm{mg}$ diaminobenzidine $\mathrm{ml}^{-1}$ (Sigma) and $0.05 \%$ hydrogen peroxide and then counterstaining with haematoxylin. The specificity of TNF staining was controlled by covering slides with normal (non-immune) rabbit serum or with the primary rabbit anti-mouse TNF- $\alpha$ antibody preincubated with 100-molar excess of recombinant mouse TNF- $\alpha$.

\section{Evaluation of apoptosis}

Apoptotic cells were visualized by TUNEL as described by Torchinsky et al. (1999). Briefly, after removal from paraffin wax, sections were dehydrated in graded 
Table 1. Morphological characteristics of embryos developing in vitro and in vivo

\begin{tabular}{|c|c|c|c|c|c|c|c|}
\hline \multirow[b]{2}{*}{ Conditions } & \multirow{2}{*}{$\begin{array}{l}\text { Number of } \\
\text { tested embryos }\end{array}$} & \multicolumn{2}{|c|}{ Heartbeat } & \multirow{2}{*}{$\begin{array}{l}\text { Number of } \\
\text { tested embryos }\end{array}$} & \multicolumn{2}{|c|}{ Neural tube } & \multirow{2}{*}{$\begin{array}{c}\text { Number of } \\
\text { somites }\end{array}$} \\
\hline & & + & - & & Closed & Open & \\
\hline Nine-day embryos developing in vivo* & 31 & $\begin{array}{c}28 \\
(90 \%)\end{array}$ & $\begin{array}{c}3 \\
(10 \%)\end{array}$ & 28 & $\begin{array}{c}28 \\
(100 \%)\end{array}$ & 0 & $26.1 \pm 0.9$ \\
\hline Age-matching embryos developing in vitro & 60 & $\begin{array}{c}50 \\
(83 \%)\end{array}$ & $\begin{array}{c}10 \\
(17 \%)\end{array}$ & 50 & $\begin{array}{c}44 \\
(88 \%)\end{array}$ & $\begin{array}{c}6 \\
(12 \%)\end{array}$ & $25.1 \pm 0.9$ \\
\hline
\end{tabular}

*Embryos from three litters of intact ICR mice were tested.

alcohols, treated with proteinase K (Amresco Inc., Solob, $\mathrm{OH})$ to hydrolyse nuclear proteins and then treated with $2 \%$ hydrogen peroxide and $0.05 \%$ Tween-20. For nick-end labelling, sections were incubated for $1 \mathrm{~h}$ with a reaction buffer containing $0.2 \mathrm{U} \mathrm{TdT} \mu \mathrm{I}^{-1}$ (Promega, Madison, WI) and $5 \mu \mathrm{mol}$ biotinylateddUTP $\mathrm{ml}^{-1}$ (Clontech Laboratories, Palo Alto, CA). For positive controls, sections were treated with $1 \mu \mathrm{g}$ DNAse $\mathrm{ml}^{-1}$, whereas for negative controls, sections were processed in the absence of TdT. Sections were blocked with $3 \%$ low fat milk and $0.05 \%$ Tween-20 in PBS, incubated with $12 \mu \mathrm{g}$ streptavidin-HRP ml ${ }^{-1}$ PBS with $0.05 \%$ Tween-20 and apoptotic cells were visualized by incubating the sections with $0.2 \mathrm{mg}$ diaminobenzidine $\mathrm{ml}^{-1}$ and $0.05 \%$ hydrogen peroxide. The number of apoptotic nuclei was counted in a blind manner in five fields by two readers in three sections collected from three different malformed or normal embryos and results were averaged.

\section{Evaluation of caspase 3 and 8 activity}

The activities of caspase 8 and 3 were measured by a caspase-8 fluorometric assay kit (R\&D systems Inc., $\mathrm{MN}$ ) and by a FluorAceTM apopain assay kit (BioRad Laboratories, Hercules, CA), respectively, according to the manufacturer's instructions. Briefly, four or five normal or malformed embryos were combined, homogenized and centrifuged at $850 \mathrm{~g}$ for $10 \mathrm{~min}$. The pellet was resuspended either in $60 \mu \mathrm{l}$ cold cell lysis buffer and incubated on ice for $10 \mathrm{~min}$ (caspase 8) or in $100 \mu \mathrm{l}$ apopain lysis buffer and then frozen and thawed four or five times (caspase 3). Protein concentration was measured using a DC protein assay kit (BioRad) and a 550 microplate reader (Bio-Rad) according to the manufacturer's instruction. Samples were frozen in aliquots in liquid nitrogen and stored at $-70^{\circ} \mathrm{C}$ until used. The measurement of both caspases was performed using a fluorescence plate reader FL-600 (Bio-Tex Instruments Inc., Winooski, VT) according to the manufacturer's instructions. The suitability of the fluorometric assay for the evaluation of the activity of the tested caspases in embryonic cells has been demonstrated with a teratogen such as cyclophosphamide (Torchinsky et al., 2002).

\section{Statistical analysis}

Fisher's exact test was used to analyse data presenting the proportion of embryos with an open neural tube. The two-tailed level of significance of differences was 0.05.

Data characterizing caspase activity were analysed by combining results obtained in samples from embryos developing in normoglycaemic medium (six samples for each tested caspase) and the average values characterizing the activity of caspase 3 or caspase 8 were calculated. Caspase activity in a sample from embryos developing in the hyperglycaemic medium (six samples for each tested caspase) was expressed as the ratio of the value recorded in a tested sample and reading to the average value characterizing the activity of a given caspase in controls. The unpaired Student's $t$ test was used for the statistical analysis of these data as well as those characterizing the number of nuclei giving a positive result in the TUNEL assay. The two-tailed level of significance of differences was 0.05.

\section{Results}

\section{Teratology}

First it was determined whether the normoglycaemic medium (100 mg glucose $\mathrm{dl}^{-1}$ ) used in the present study would support normal embryonic development. For this, the growth and development of embryos cultured for $24 \mathrm{~h}$ and those of age-matched intact embryos developing in vivo was compared. It was observed (Table 1) that $90 \%$ of embryos developing in vivo demonstrated a heartbeat and all exhibited a closed neural tube. These values were slightly lower in cultured embryos but the differences were not statistically significant (Table 1 ).

The teratogenic potential of glucose was evaluated by culturing embryos for $24 \mathrm{~h}$ with glucose at 500, 800 or $1300 \mathrm{mg} \mathrm{dl}^{-1}$ and the embryos were examined for the incidence of an open neural tube as a characteristic of glucose-induced maldevelopment. The proportion of embryos exhibiting an open neural tube increased in a concentration-dependent fashion, from $37 \%$ among embryos cultured with $500 \mathrm{mg}$ glucose $\mathrm{dl}^{-1}$ to $97 \%$ among embryos exposed to the highest concentration of glucose, $1300 \mathrm{mg} \mathrm{dl}^{-1}$ (Table 2). In addition, a 
Table 2. The influence of glucose on embryonic development

\begin{tabular}{lcccc}
\hline $\begin{array}{l}\text { Glucose } \\
\left(\mathrm{mg} \mathrm{dl}^{-1}\right)\end{array}$ & $\begin{array}{c}\text { Embryos } \\
\text { examined }\end{array}$ & $\begin{array}{c}\text { Embryos with } \\
\text { heartbeat }\end{array}$ & $\begin{array}{c}\text { Embryos with } \\
\text { open neural } \\
\text { tube }\end{array}$ & $\begin{array}{c}\text { Number of } \\
\text { somites }\end{array}$ \\
\hline 100 (control) & 60 & $50(83 \%)$ & $6(12 \%)$ & $25.1 \pm 0.9$ \\
500 & 20 & $19(95 \%)$ & $7(37 \%)^{*}$ & $23.2 \pm 0.8$ \\
800 & 24 & $22(92 \%)$ & $15(68 \%)$ & $21.4 \pm 0.7^{\dagger}$ \\
1300 & 66 & $60(91 \%)$ & $58(97 \%)$ & $18.6 \pm 0.4^{\dagger}$ \\
\hline
\end{tabular}

*Significantly different from controls $(P=0.02)$.

$\dagger$ Significantly different from controls $(P<0.05)$.
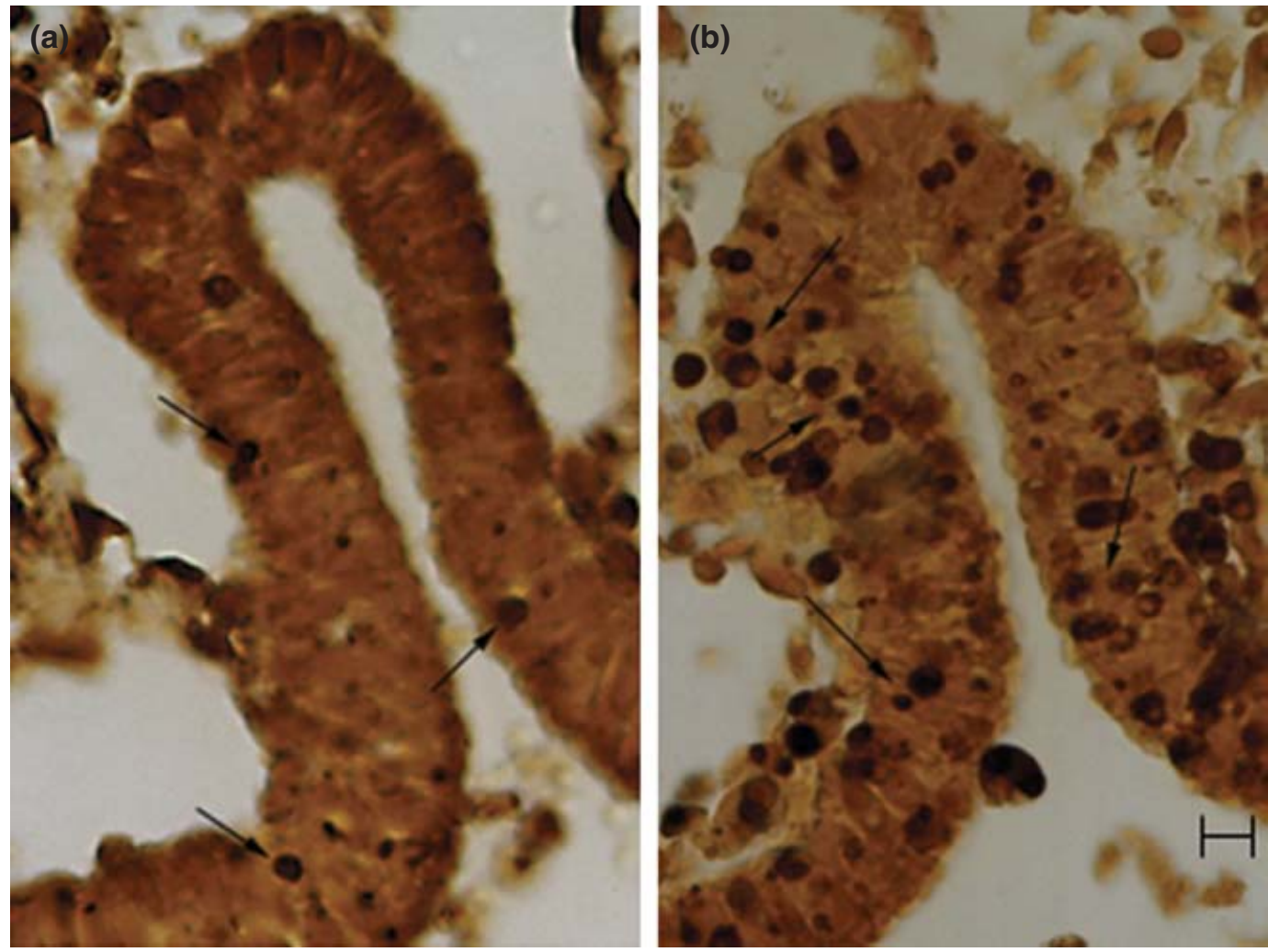

Fig. 1. Apoptotic nuclei (arrows) in the neuroepithelial layer (NE) of the wall of infundibular recess of the diencephalon in (a) control and (b) malformed mouse embryos visualized by TdT-mediated dUTP nick-end labelling. Scale bar represents $200 \mu \mathrm{m}$.

significant decrease in the number of somites was recorded in embryos cultured with glucose at 800 and $1300 \mathrm{mg} \mathrm{dl}^{-1}$ (approximately, $21.4 \pm 0.7$ and $18.6 \pm 0.4$, respectively, versus $25.1 \pm 0.9$ in controls).

Embryos cultured in media with glucose at $800 \mathrm{mg}$ $\mathrm{dl}^{-1}$ were used to evaluate caspase activity as well as apoptosis and TNF- $\alpha$ expression.

\section{Evaluation of apoptosis}

Only single nuclei positive in the TUNEL assay were observed in the neuroepithelial layer of the wall of the infundibular recess of the diencephalon of normal embryos and a large cluster of these nuclei was found in the neuroepithelial layer of embryos with open neural folds (Fig. 1). The number of nuclei positive in the TUNEL assay was estimated to be $28 \pm 5$ per field of vision in the neuroepithelium of malformed embryos and $4 \pm 1$ in normal embryos.

Analysis of caspase activity (Fig. 2) showed that $16 \mathrm{~h}$ after the beginning of culture, the activities of caspase 8 and caspase 3 in embryos cultured with $800 \mathrm{mg}$ glucose $\mathrm{dl}^{-1}$ were equal to those in controls. After $24 \mathrm{~h}$ of culture, the activity of caspase 8 was significantly higher in malformed compared with normal embryos, while the activity of caspase 3 at this time point did not differ between normal and malformed embryos (Fig. 2). 

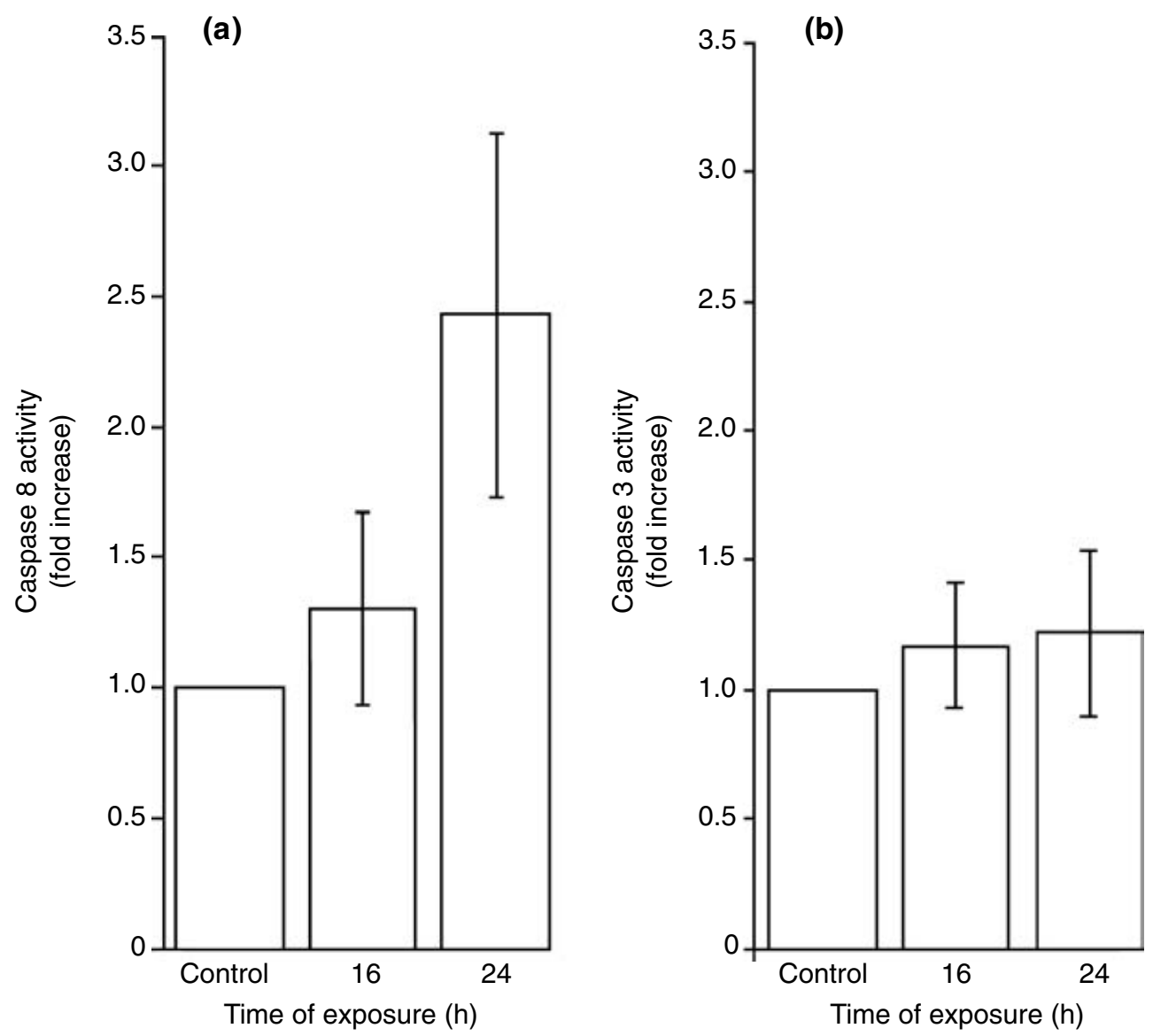

Fig. 2. Caspase activity in control mouse embryos or mouse embryos exposed to $800 \mathrm{mg}$ glucose $\mathrm{dl}^{-1}$ in vitro. (a) Caspase 8; (b) caspase 3. Caspase activity in a sample from embryos developing in the hyperglycaemic medium (six samples for each caspase) was expressed as the ratio of the value recorded in a tested sample and the average value characterizing the activity of a given caspase in controls, which was obtained by evaluating five samples for each caspase. Results are means with 95\% limits. Means with limits that do not overlap are significantly different. Means with lower limits $\leqslant 1$ (the amount of caspase activity in controls) do not differ significantly from controls.

\section{$T N F-\alpha$ protein expression}

TNF- $\alpha$ expression in cultured embryos was identified by preparing and staining histological sections of normal and malformed embryos with anti-TNF- $\alpha$ antibodies. Strong immunoreactivity was detected in the neuroepithelial layer of embryos having an open neural tube, whereas the expression of this cytokine was weak, if detectable, in embryos with a closed neural tube cultured in the normoglycaemic medium (Fig. 3). TNF- $\alpha$ expression did not increase in normal embryos cultured in the hyperglycaemic medium (data not presented).

\section{Discussion}

Almost any developing organ can be affected by maternal diabetes but neural tube defects (NTDs), including anencephaly and spina bifida, are among the most common that occur (Kousseff, 1999). Studies of models in vitro and in vivo demonstrate that one of the main early dysmorphic events preceding the occurrence of fetuses with these anomalies is the failure of neural tube closure in early postimplantation embryos (Juriloff and Harris, 2000).

In the present study, approximately $40 \%$ of embryos cultured in the presence of $500 \mathrm{mg} \mathrm{dl}^{-1}$ glucose for $24 \mathrm{~h}$ exhibited open neural folds. The proportion of embryos with this anomaly reached $70 \%$ if the glucose concentration was $800 \mathrm{mg} \mathrm{dl}^{-1}$ and the highest glucose concentration $\left(1300 \mathrm{mg} \mathrm{dl}^{-1}\right)$ induced this anomaly in nearly all embryos.

These results demonstrating the ability of glucose to induce NTDs in mouse embryos in a dose-dependent fashion concur with those obtained in studies with rat and mouse embryos cultured with different glucose concentrations (Styrud and Eriksson, 1992; Hunter and Sadler, 1992). They are also in agreement with other in vivo studies (Torchinsky et al., 1997; Machado et al., 

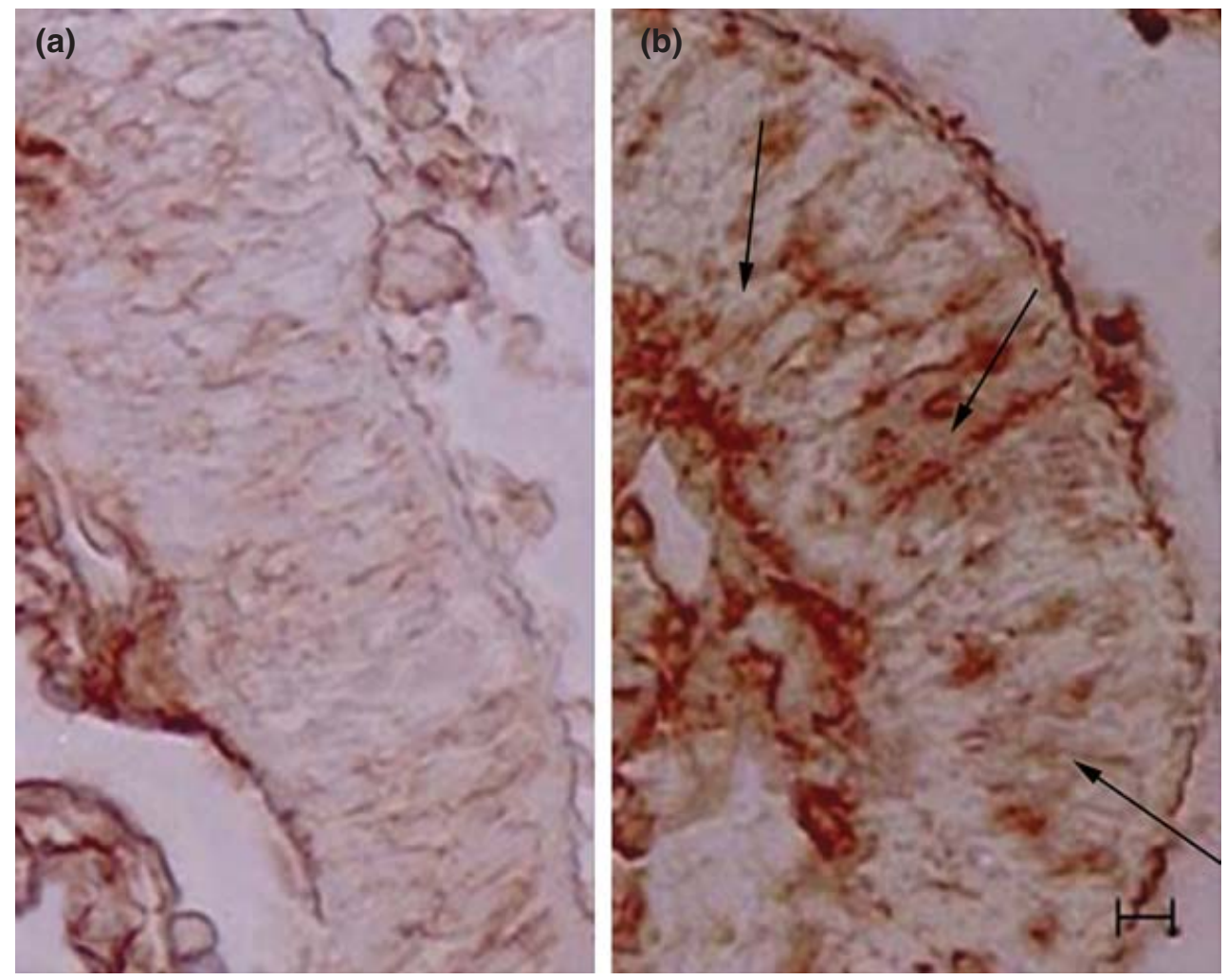

Fig. 3. Immunohistochemical analysis of tumour necrosis factor $\alpha$ (TNF- $\alpha$ ) protein expression (arrows) in neuroepithelial layer of the wall of infundibular recess of the diencephalon in (a) control and (b) malformed mouse embryos. The scale bar represents $100 \mu \mathrm{m}$.

2001), which demonstrated a direct correlation between glucose concentration in maternal blood and the appearance of NTDs in fetuses tested at the end of the antenatal period. The existence of such a correlation does not exclude the possibility that factors such as somatomedinbinding proteins, $\beta$-hydroxybutyrate or disturbances in yolk sac structure or physiology could also be factors involved in triggering the process of diabetes-induced maldevelopment (Eriksson et al., 2000). However, the teratogenic potential of glucose is strongly indicated.

In the present work, an increased TNF- $\alpha$ expression was found in embryos exhibiting excessive apoptosis and an open neural tube after culture with high glucose concentrations but not in embryos that demonstrated normal development in these conditions. While discussing these findings, it should first be mentioned that excessive apoptosis was observed earlier in the mid- and hindbrain of embryos of streptozoticin-treated diabetic mice and those of mice injected with glucose, which exhibited an open neutral tube (Phelan et al., 1997; Fine et al., 1999), indicating that this excessive apoptosis may be an integral part of the process leading to the formation of diabetes-induced NTDs.

In addition, a number of studies have demonstrated that excessive apoptosis in embryos and extraembryonic tissues of females exposed to an embryopathic stress may be accompanied by an increased expression of TNF- $\alpha$. An increased expression of TNF- $\alpha$ and TNFRI mRNA and excessive apoptosis in uterine and placental cells of mice with induced and spontaneous pregnancy loss have been reported previously (Gorivodsky et al., 1998; Savion et al., 2002). An increased expression of TNF- $\alpha$ at the mRNA and protein level and also TNFR1 mRNA transcripts have been observed in the embryo after exposure to cyclophosphamide in doses that induce excessive apoptosis in embryonic structures that become malformed (Ivnitsky et al., 1998; Torchinsky et al., 2002). Finally, an increased expression of TNF- $\alpha$ has also been observed in the embryonic microenvironment of diabetic mice (Pampfer et al., 1995; Pampfer, 2001; Fein et al., 2001) and, in parallel, an increased apoptosis was detected in blastocyts developing in vitro and in vivo under hyperglycaemic conditions (Moley, 2001).

In the light of all the above data, it is possible that the finding of increased expression of TNF- $\alpha$ and excessive apoptosis in malformed but not in normal embryos cultured with teratogenic concentrations of glucose indicates an involvement of this cytokine in regulation of the teratogenic response to glucose.

TNF- $\alpha$ has the potential to activate the apoptotic pathway by binding mainly to TNFR1 (Baud and Karin, 2001; Gupta, 2001). The expression of TNFR1 in 
embryos during organogenesis has been demonstrated (Kohchi et al., 1994). Furthermore, the teratogenic effect induced by cyclophosphamide is accompanied by an increased expression of TNF- $\alpha$ and TNFR1 in the teratogen-targeted embryonic organs (Ivnitsky et al., 1998). The role of caspase 8 in mediating apoptosis triggered via receptors belonging to the TNFR family has been demonstrated (Baud and Karin, 2001; Gupta, 2001). In turn, caspase 3 could be an effector caspase activated by the initiator caspase 8 (Baud and Karin, 2001; Gupta, 2001). Studies with cyclophosphamide have shown that excessive apoptosis in embryonic structures that become malformed is accompanied by an increased expression of TNF- $\alpha$, and by activation of caspases 3 and 8 (Torchinsky et al., 2002). On the basis of these data the possibility was tested that these caspases are activated in early postimplantation embryos that are exposed to hyperglycemic conditions.

In the present study, activation of caspase 8 was found in embryos after $24 \mathrm{~h}$ in culture with teratogenic concentrations of glucose, when they exhibited an open neural tube. This finding might indicate an involvement of caspase 8 in mediating glucose-induced maldevelopment. However, an increased activity of caspase 8 was not found in embryos cultured for $16 \mathrm{~h}$ in the medium with high glucose concentration. As control embryos tested at this time point still exhibited an open neural tube, this result may indicate that events preceding the occurrence of the anomaly (open neural tube), such as activation caspases and hence excessive apoptosis, might take place in the period between 16 and $24 \mathrm{~h}$ after initiating the culture.

In addition, activation of caspase 3 was not observed; the reasons for this result are unclear. Studies with cyclophosphamide (Torchinsky et al., 2002) have shown (i) that it activates caspase 3 and caspase 8 in the embryonic brain in a dose-dependent fashion, (ii) that the extent of cyclophosphamide-induced activation of caspase 8 is greater than of caspase 3, and (iii) that low doses of cyclophosphamide induce apoptosis and activate caspase 8 but not caspase 3 . In the light of these data, it is possible that the teratogenic effect of glucose in the present study did not reach the intensity needed to activate caspase 3 . Such a possibility is also indicated by findings of a study performed in streptozoticin-treated diabetic mice (Mohr et al., 2002), which revealed that activation of initiator caspases such as caspase 8 and caspase 9 occurred earlier in the course of diabetes than that of caspase 3. On the other hand, there is evidence that caspase 8 acts as an initiator caspase and as an effector caspase (Slee et al., 1999) and that activation of caspase 3 is not indispensable for triggering apoptosis in some types of cell (Woo et al., 1998; Zheng et al., 1998).

In the light of the above, it seems that caspase 8 may be among the first targets in further in-depth studies addressing the functional role of TNF- $\alpha$-mediated apoptotic pathways in the response of embryos to glucose-induced teratogenic stress.

However, TNF- $\alpha$-induced receptor activation is not the only path leading to activation of caspase 8 . Thus, caspase 8 was shown to be activated early in cells undergoing p53-mediated apoptosis (Vousden, 2000). In addition, Pani et al. (2002) suggested that diabetes-induced excessive apoptosis in postimplantation embryos may result from distortions in the Pax3 transcription factor-mediated regulation of p53 leading to activation of p53-mediated apoptosis. Furthermore, TNF- $\alpha$ is capable of generating not only a death receptormediated apoptotic but also an anti-apoptotic signalling cascade (Baud and Karin, 2001). These facts need to be considered in further studies addressing the functional role of TNF- $\alpha$ in the regulation of the response of embryos to diabetes-induced teratogenic stress.

In conclusion, the present study revealed an increased expression of TNF- $\alpha$ in embryos at the time of their particular vulnerability for glucose-generated teratogenic stimuli, indicating that this cytokine may be involved in the process of the formation of diabetes-induced structural birth defects. Further studies are required to test this hypothesis.

This work was supported by grants from The Israel Science Foundation founded by the Israel Academy of Sciences and Humanities (grant \#541/00) and the Israel Ministry of Health.

\section{References}

Baud V and Karin M (2001) Signal transduction by tumor necrosis factor and its relatives Trends in Cell Biology 11 372-377

Eriksson UJ, Borg LA, Cederberg J, Nordstrand H, Siman CM, Wentzel C and Wentzel P (2000) Pathogenesis of diabetes-induced congenital malformations Upsala Journal of Medical Sciences $\mathbf{1 0}$ 53-84

Fein A, Kostina E, Savion S, Orenstein H, Shepshelovich J, Ornoy A, Torchinsky A and Toder V (2001) Expression of tumor necrosis factor- $\alpha$ in the uteroplacental unit of diabetic mice: effect of maternal immunopotentiation American Journal of Reproductive Immunology $\mathbf{4 6}$ $161-168$

Fine EL, Horal M, Chang TI, Fortin G and Loeken MR (1999) Evidence that elevated glucose causes altered gene expression, apoptosis, and neural tube defects in a mouse model of diabetic pregnancy Diabetes 48 2454-2462

Gorivodsky M, Zemliak I, Orenstein H, Savion S, Fein A, Torchinsky A and Toder V (1998) Tumor necrosis factor alpha mRNA and protein expression in the uteroplacental unit of mice with pregnancy loss Journal of Immunology 160 4280-4288

Green DR (1998) Apoptotic pathways: the roads to ruin Cell 94 695-698

Greene MF, Hare JW, Cloherty JP, Benacerraf BR and Soeldner JS (1989) First trimester haemoglobin A1 and risk for major malformation and spontaneous abortion in diabetic pregnancy Teratology 39225 231

Gupta S (2001) Molecular steps of tumor necrosis factor receptor-mediated apoptosis. Current Molecular Medicine 1 317-324

Hunter ES III and Sadler TW (1992) The role of the visceral yolk sac in hyperglycemia-induced embryopathies in mouse embryos in vitro. Teratology 45 195-203

Ivnitsky I, Torchinsky A, Gorivodsky M, Zemliak I, Orenstein H, Savion S, Shepshelovich J, Carp H, Fein A and Toder V (1998) TNF- $\alpha$ expression in embryos exposed to a teratogen American Journal of Reproductive Immunology 40 1-10 
Juriloff DM and Harris MJ (2000) Mouse models for neural tube closure defects Human Molecular Genetics 9 993-1000

Kjos SL and Buchanan TA (1999) Gestational diabetes mellitus New England Journal of Medicine 341 1749-1756

Kohchi C, Noguchi K, Tanabe Y, Mizuno DI and Soma GI (1994) Constitutive expression of TNF- $\alpha$ and $-\beta$ genes in mouse embryos: role of cytokines as regulators and effectors on development International Journal of Biochemistry and Cell Biology 26 111-119

Kousseff BG (1999) Gestational diabetes mellitus (class A): a human teratogen? American Journal of Medical Genetics 83 402-408

Langer $\mathbf{O}$ and Conway DL (2000) Level of glycemia and perinatal outcome in pregestational diabetes Journal of Maternal-Fetal Medicine 9 3541

Machado AF, Zimmerman EF, Hovland DN, Jr, Weiss $\mathbf{R}$ and Collins MD (2001) Diabetic embryopathy in C57BL/6J mice. Altered fetal sex ratio and impact of the splotch allele Diabetes 50 1193-1199

Mirkes PE (2002) 2001 Warkany lecture: to die or not to die, the role of apoptosis in normal and abnormal mammalian development Teratology $65228-239$

Mohr S, Xi X, Tang J and Kern TS (2002) Caspase activation in retinas of diabetic and galactosemic mice and diabetic patients Diabetes $\mathbf{5 1}$ 1172-1179

Moley KH (2001) Hyperglycemia and apoptosis: mechanisms for congenital malformations and pregnancy loss in diabetic women Trends in Endocrinology and Metabolism 12 78-82

New DA (1978) Whole-embryo culture and the study of mammalian embryos during organogenesis Biological Reviews of the Cambridge Philosophical Society 53 81-122

Pampfer S (2001) Dysregulation of the cytokine network in the uterus of the diabetic rat American Journal of Reproductive Immunology 45 375381

Pampfer S, Wuu YD, Vanderheyden I and De Hertogh R (1994) Expression of tumor necrosis factor-alpha (TNF alpha) receptors and selective effect of TNF alpha on the inner cell mass in mouse blastocysts Endocrinology 134 206-212

Pampfer S, Vanderheyden I, Wuu Y, Baufays L, Maillet $O$ and De Hertogh R (1995) Possible role for TNF-alpha in early embryopathy associated with maternal diabetes in the rat Diabetes 44 531-536

Pampfer S, Vanderheyden I, McCracken JE, Vesela J and De Hertogh R (1997) Increased cell death in rat blastocysts exposed to maternal diabetes in utero and to high glucose or tumor necrosis factor-alpha in vitro. Development 124 4827-4836

Pani L, Horal M and Loeken MR (2002) Rescue of neural tube defects in Pax-3-deficient embryos by p53 loss of function: implications for Pax-3 dependent development and tumorigenesis Genes and Development 16 676-680

Phelan SA, Ito M and Loeken MR (1997) Neural tube defects in embryos of diabetic mice: role of the Pax-3 gene and apoptosis Diabetes 461189 1197
Pomerantz JL and Baltimore D (2000) Signal transduction. A cellular rescue team Nature 406 26-27, 29

Reece EA, Homko CJ and Wu YK (1996) Multifactorial basis of the syndrome of diabetic embryopathy Teratology 54 171-182

Sadler TW (1997) Mouse embryos in culture: models for understanding diabetes-induced embryopathies and gene function International Journal of Development Biology 41 291-297

Savion S, Lepsky E, Orenstein H, Carp H, Shepshelovich J, Torchinsky A, Fein A and Toder V (2002) Apoptosis in the uterus of mice with pregnancy loss American Journal of Reproductive Immunology 47118 127

Slee EA, Adrian C and Martin SJ (1999) Serial killers: $\gamma$ ordering caspase activation events in apoptosis Cell Death and Differentiation 111067 1074

Styrud J and Eriksson UJ (1992) Development of rat embryos in culture media containing different concentrations of normal and diabetic rat serum Teratology 46 473-483

Toder V, Fein A, Carp H and Torchinsky A (2002) The role of pro- and anti-apoptotic molecular interactions in embryonic maldevelopment American Journal of Reproductive Immunology 48 234-244

Torchinsky A, Toder V, Carp H, Orenstein H and Fein A (1997) In vivo evidence for the existence of a threshold for hyperglycemiainduced major fetal malformations: relevance to the etiology of diabetic teratogenesis Early Pregnancy 3 27-33

Torchinsky A, Ivnitsky I, Savion S et al. (1999) Cellular events and the pattern of p53 protein expression following cyclophosphamide-initiated cell death in various organs of the developing embryo Teratogenesis, Carcinogenesis and Mutagenesis 19 353-367

Torchinsky A, Lishanski L, Wolstein O et al. (2002) NF-kappaB DNA-binding activity in embryos responding to a teratogen, cyclophosphamide BioMed Central Developmental Biology 22

Vousden KH (2000) p53: death star Cell 103 692-694

Woo M, Hakem R, Soengas MS et al. (1998) Essential contribution of caspase 3/CPP32 to apoptosis and its associated nuclear changes Genes and Development 12 806-819

Wuu YD, Pampfer S, Becquet P, Vanderheyden I, Lee KH and De Hertogh $\mathbf{R}$ (1999) Tumor necrosis factor alpha decreases the viability of mouse blastocysts in vitro and in vivo. Biology of Reproduction $60479-483$

Zheng TS, Shlosser SF, Hingorani R, Crispe AN, Boyer GL and Flavell RA (1998) Caspase- $\gamma 3$ controls both cytoplasmic and nuclear events associated with Fas-mediated apoptosis in vivo. Proceedings National Academy of Sciences USA 9513 618-13 623

Received 29 August 2002.

First decision 28 October 2002.

Revised manuscript received 3 December 2002.

Accepted 20 December 2002. 